\title{
Anaesthetic Concerns in a Child Posted for Suprasellar Tumour Resection
}

\author{
Priyanka Sethi, Balakrishnan N, Manbir Kaur ${ }^{*}$, Kalyani Manasa Rapeti
}

Department of Anesthesia and Critical Care, All India Institute of Medical Sciences (AIIMS), Jodhpur, Rajasthan, India

DOI: $10.36347 /$ sjams.2021.v09i03.027

| Received: 16.02.2021 | Accepted: 27.02.2021 | Published: 21.03.2021

*Corresponding author: Dr. Manbir Kaur

Letter to Editor

Copyright $\left({ }_{0} 2021\right.$ The Author(s): This is an open-access article distributed under the terms of the Creative Commons Attribution 4.0 International License (CC BY-NC 4.0) which permits unrestricted use, distribution, and reproduction in any medium for non-commercial use provided the original author and source are credited.

SIR,

Craniopharyngiomas are rare histologically benign intracranial neoplasms usually presenting as sellar and/or suprasellar mass lesions. They occur most commonly in children between 5-10 years [1]. The majority of patients present with neurological symptoms such as headache, vision loss, and endocrinological problems such as hypernatremia due to diabetes insipidus (DI) [1]. The effectual management of fluid and electrolyte disturbances occurring in these patients during perioperative period requires an alert and well-informed intensivist. We hereby report anaesthetic implications in a case of 16 years old male, electively posted for craniopharyngioma resection.

A 16-years-old male presented to the ophthalmology department with complaints of headache and progressive diminution of vision for the past two months. On examination, the left eye had no vision (projection to light (PL) negative with primary optic atrophy), and in right eye visual acuity was $6 / 6$. Magnetic resonance imaging (MRI) of the brain revealed a sellar/suprasellar mass of size $34 \mathrm{~mm} \times$ $22 \mathrm{~mm} \times 20 \mathrm{~mm}$, compressing the optic chiasma with no hydrocephalus. Considering the clinico-radiological picture, a provisional diagnosis of craniopharyngioma was made. The Endocrinological examination revealed hypothyroidism, so he was started on thyroxine 25 $\mathrm{mcg}$ /day. Elective surgery was planned one week after starting thyroxine.

After ensuring adequate fasting, the patient was taken to the operation theatre, and monitors as per the American society of anesthesiologists (ASA) guidelines were attached. The patient was induced with propofol $2 \mathrm{mg} / \mathrm{kg}$, fentanyl $2 \mathrm{mcg} / \mathrm{kg}$ and rocuronium $0.5 \mathrm{mg} / \mathrm{kg}$. Anaesthesia was maintained with air oxygen mixture and isoflurane with an end-tidal concentration of 1.0. Half normal saline was used intraoperatively in contrast to the usual normal saline [2]. As per the endocrinologist's advice, hydrocortisone infusion was started @3 mg/hr and continued till the end of surgery because of a low cortisol level. Left frontotemporal craniotomy and tumor excision were done.

The urine output of the patient was $1 \mathrm{ml} / \mathrm{kg} / \mathrm{hr}$ throughout the surgery; however, it started to increase in the immediate postoperative period. The patient was shifted to the pediatric intensive care unit (PICU) for postoperative monitoring. After 12 hours, the patient was extubated. Post extubation, the patient responded to verbal commands. In the postoperative period, the patient developed diabetes insipidus (DI), which was managed with six-hourly serum sodium measurement, hourly urine output monitoring and intranasal desmopressin given two times a day. Postoperative radiography revealed no residual tumour, and the histopathology report was suggestive of craniopharyngioma. The patient's DI was transient and resolved in a few days, after which desmopressin was stopped. Tablet thyroxine was continued in view of hypothyroidism. The patient was discharged on day 10 .

Craniopharyngiomas are benign (WHO grade I) sellar/suprasellar neoplasms [3]. Though benign, their location in proximity to important neurovascular structures and hypothalamus makes their excision challenging like other skull base tumors [4]. For an anaesthesiologist/intensivist, an important concern in these patients is the occurrence \& management of DI in the postoperative period (Figure 1). Surgical manipulation in the sellar/suprasellar region with consequent handling of the pituitary stalk often results in the decreased secretion of anti-diuretic hormone $(\mathrm{ADH})$. Deficiency of $\mathrm{ADH}$ in turn results in the development of central DI. Fortunately this disturbance in the secretion of ADH from posterior pituitary is most 
Priyanka Sethi et al; Sch J App Med Sci, Mar, 2021; 9(3): 433-434

often transient (as in our case). However, increased urine output and resulting increased serum sodium during this period if not managed properly can be lethal. Hypernatremia can lead to the development of seizures and even coma. In neurological surgery, apart from acetazolamide induced electrolyte disturbances, DI is the most important condition causing fluid and electrolyte disturbances [5].

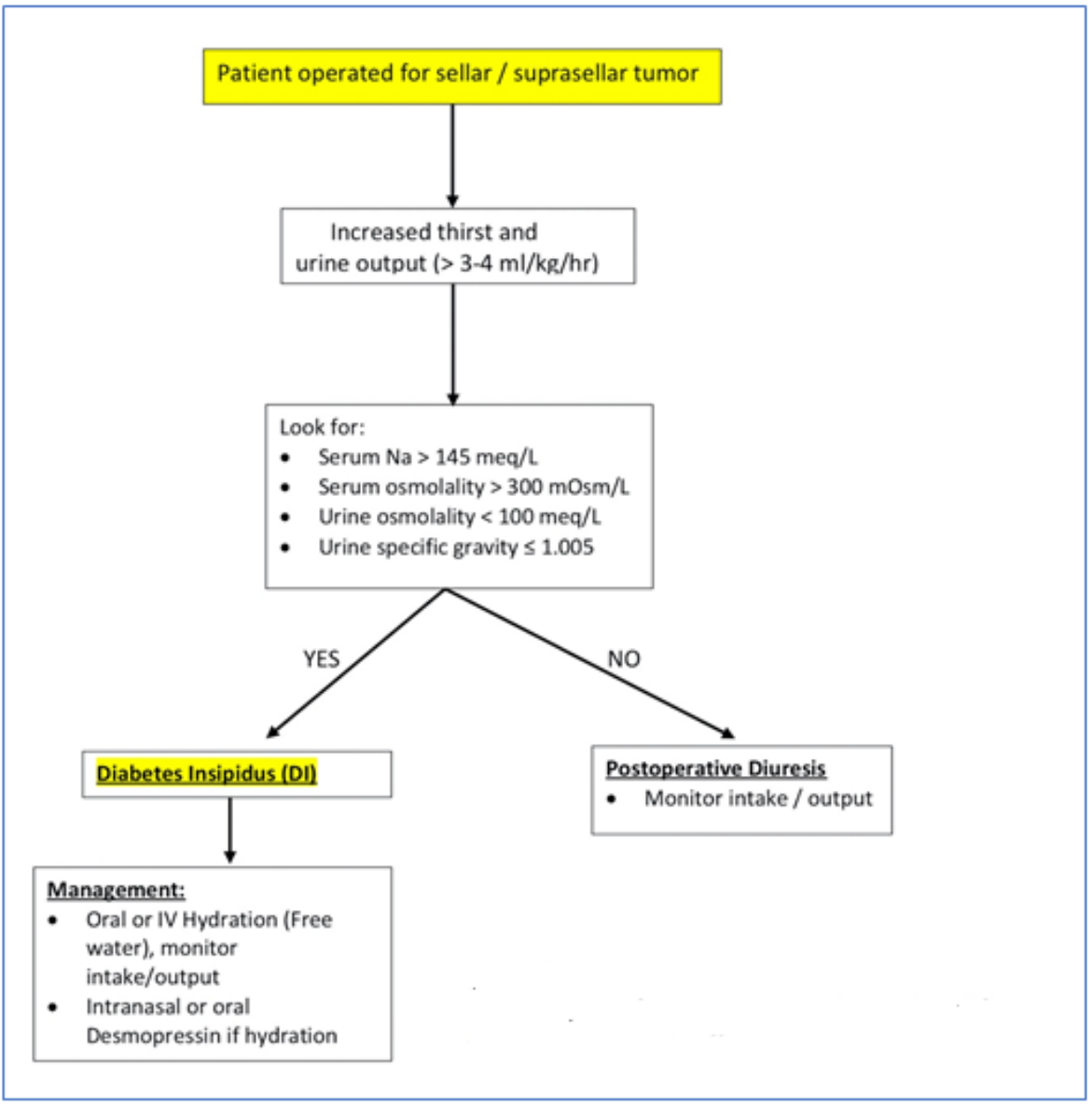

Fig-1: Simple step-wise diagnostic \& management algorithm for diabetes insipidus (DI) after sellar/suprasellar surgery

In the setting of sellar/suprasellar surgery, DI is diagnosed when patient has i) increased thirst with increased urine output $(>4 \mathrm{ml} / \mathrm{kg} / \mathrm{hr}$ for 3 consecutive hours), ii) increased serum sodium (>145 meq/L) with increased serum osmolality $(>300 \mathrm{mOsm} / \mathrm{L})$, iii) decreased urine osmolality $(<100 \mathrm{mOsm} / \mathrm{L})$ [3]. Usually the DI is self-limited and is managed with adequate free water intake and administration of desmopressin.

The perioperative period, especially the postoperative, is a crucial phase for intensivists in sellar/suprasellar patients, as there are chances of development of DI with consequent hypernatremia due to pituitary dysfunction. As intensivists, we should be aware of these alterations, since if diagnosed and treated promptly, mortality and morbidity can be reduced.

\section{REFERENCES}

1. Moningi S. Anaesthetic management of children with craniopharyngioma. J Neuroanaesth Crit Care. 2017;4:30-37.
2. Mukherjee KK, Dutta P, Singh A, Gupta P, Srinivasan A, Bhagat H. Choice of fluid therapy in patients of craniopharyngioma in the perioperative period: A hospital-based preliminary study. Surg Neurol Int. 08-Jul-2014; 5:105.

3. Wisoff JH, Donahue BR. Craniopharyngiomas. In: Albright AL, Pollack IF, Adelson PD, eds. Principles and Practice of Pediatric Neurosurgery. 2nd ed. New York, Stuttgart: Thieme. 2006:560 577.

4. Gosal JS, Behari S, Joseph J, Jaiswal AK, Sardhara JC, Iqbal M. Surgical excision of large-to-giant petroclival meningiomas focusing on the middle fossa approaches: The lessons learnt. Neurol India. 2018;66(5):1434-1446.

5. Gosal JS, Gurmey T, Kursa GK, Salunke P, Gupta SK. Is acetazolamide really useful in the management of traumatic cere brospinal fluid rhinorrhea? Neurol India. 2015;63(2):197-201. 